\title{
Clinician and Staff Perceptions of Barriers to Providing Contraception in Primary Care
}

\author{
Lauren Cowen | Scott G. Hartman, MD | Elizabeth Loomis, MD | Sukanya Srinivasan, MD, MPH | \\ Christina Gasbarro, MD I Jocelyn Young, DO
}

PRiMER. 2019;3:2.

Published: 2/8/2019 | DOI: 10.22454/PRiMER.2019.228141

\section{Abstract}

Introduction: Short interpregnancy periods increase the likelihood of preterm delivery and low birth weight, ${ }^{1}$ both of which are significant causes of infant morbidity and mortality. ${ }^{2}$ Since nearly half of pregnancies in the United States are unplanned, ${ }^{3}$ opportunities exist to better understand barriers to contraceptive services. Studying these barriers as perceived by clinical staff can better guide programs to improve interpregnancy spacing.

Methods: Between September and November 2017, 76 staff and 95 primary care clinicians from two family medicine residency practices (Highland Family Medicine (HFM) in Rochester, New York and St Margaret Family Medicine (SM) in Pittsburgh, Pennsylvania) completed surveys. Questions assessed perceived barriers to providing contraceptive services, contraception knowledge, and opportunities for improvement. Survey-based analysis focused on comparative descriptive statistics between staff and provider responses.

Results: Clinicians ranked side effects and patient lack of awareness and misconceptions about contraceptive methods more highly than staff ( $P=0.0073$ and $P=0.0001$, respectively). Staff identified childcare and work absence as more significant barriers ( $P=0.0114$ and $P=0.0380$, respectively). Providers felt appointment timing was the largest constraint to contraceptive care. Staff perceived financial limitations and scheduling to be the top barriers. Nonclinician staff exhibited significant knowledge gaps regarding contraception.

Conclusions: Numerous modifiable barriers contribute to difficulty providing contraceptive services. Providers and staff largely agree on the perceived barriers, but there is a significant gap in nonclinician staff knowledge of contraception. Education can address one of the leading concerns, but improvement efforts should also address areas such as availability of devices, scheduling issues, and resident supervision.

\section{Introduction}

Family planning and adequate birth spacing serve as critical aspects of women's reproductive health. Unintended pregnancies result in an increased number of premature/low birth weight infants, decreased rates of breastfeeding, and increased risks of physical and mental illness in children. Shortened interpregnancy periods increase the likelihood of preterm delivery and low birth weight, ${ }^{1}$ which contribute significantly to infant morbidity and mortality. ${ }^{2}$ Between 2008 to 2012, use of highly effective long-acting reversible contraceptive (LARC) methods was associated with a period of decline in unintended pregnancies. ${ }^{3}$ Despite this decline, $45 \%$ of pregnancies in the United States remain unplanned. ${ }^{3}$ The IMPLICIT Network has developed an innovative, evidence-based approach to interconception care by screening mothers during their babies' well-child visits, addressing risk factors such as provision of effective contraceptive methods to ensure adequate birth spacing. ${ }^{4}$ Network data demonstrates that 
use of contraception rapidly declines after the first 6 weeks postpartum. ${ }^{5}$ More effective strategies must be developed to provide access to contraception during this period.

Background literature has identified a variety of challenges based upon patient and health center factors. Patientrelated barriers include misconceptions about contraceptive methods, appointment access, lack of insurance, and cultural and religious beliefs. Health center barriers include cost, limited LARC device availability, and obstacles to same-day LARC initiation. Providers encounter challenges in patient-provider communication, adequate training, knowledge gaps regarding safety, appropriateness of candidates, and confidentiality for adolescents. ${ }^{6-14} \mathrm{~A}$ paucity of literature exists examining the impacts of nonclinician staff knowledge on contraception access. Our study examined barriers perceived by health care providers and staff at two family health centers in order to identify clinicspecific challenges and improve patient access to contraception.

\section{Methods}

We developed two surveys for providers and staff available from the STFM Resource Library. ${ }^{15}$ We designed the surveys with consideration of barriers previously identified in the literature and input from local experts and office staff. We investigated barriers in two different ways to provide internal consistency and included free response options. Ranking score maximum numbers varied by question depending on how many potential barriers were listed as options for selection. Participant demographics and general contraception knowledge was also collected. Eligibility criteria included current employment at one of two residency affiliated family health centers: Highland Family Medicine (HFM) in Rochester, New York or St Margaret Family Medicine (SM) in Pittsburgh, Pennsylvania. Participants were recruited by email invitation and asked to complete the electronic survey via the SurveyMonkey platform. Analysis focused on comparative descriptive statistics between staff and health care provider responses. The University of Rochester and University of Pittsburgh's institutional review boards exempted this study of quality improvement. All participants completed the survey between September and November of 2017.

\section{Results}

A total of 171 health care providers and staff submitted responses to the survey, of which 146 surveys were completely answered. Table 1 includes respondent demographics. The survey response rate was $67.1 \%$ (providers: $57.9 \%$, staff: $83.5 \%$ )

The participants' ranking of perceived barriers demonstrated largely concordant responses for providers and staff at both residencies. Providers felt misconceptions about contraceptive methods and side effects posed the top patient barriers to contraceptive care access. When combining data from both health centers, we found four statistically significant differences between providers and staff (Figure 1). Providers ranked misconceptions about contraceptive methods and side effects more highly than staff $(P=0.0073$ and $P=0.0001$, respectively). Staff identified childcare and absence from work as more significant barriers than providers did ( $P=0.0114$ and $P=0.0380$, respectively). Staff at both sites also reported a lack of patient self-motivation. Providers felt appointment timing was the largest constraint on their ability to provide contraception (Figure 2). Staff questions included additional barriers they would more directly encounter, all of which survey participants identified as relevant (financial, stocking supplies, scheduling, room availability; Figure 3).

Nonclinician staff exhibited knowledge gaps regarding contraception with $32 \%$ of staff respondents incorrectly indicating that prophylactic antibiotics are recommended for intrauterine device (IUD) insertion, 38\% incorrectly listing prior ectopic pregnancy as a contraindication for IUD, 55\% responding that immediate postpartum LARC is unsafe, and $30 \%$ answering that a Pap smear is required for IUD insertion. Providers also had knowledge gaps specifically regarding requirements for a Pap smear (up to $14 \%$ answered incorrectly at one site) and sexually transmitted infection testing (35\% incorrect) for IUD insertion (Table 2). 


\section{Conclusions}

Our findings highlight modifiable factors that decrease patient contraception access. Participants identified many of the factors already noted in medical literature, but the additional ranking findings enabled characterization of factors that might be considered the greatest challenges at specific clinic sites. This data can facilitate the ability to target site-specific interventions to modify factors.

As predicted by level of training, providers generally demonstrated a solid knowledge base regarding contraception. However, a significant gap existed in staff knowledge regarding intrauterine devices. This inadequate knowledge may lead to inaccurate patient counseling, inappropriate scheduling, and delayed care.

We note several limitations with this study. Providers who indicated they do not provide maternity care represented the majority of the incomplete health care provider surveys. Upon review of individual responses, some apparent misinterpretations existed with the survey's ranking system, either noted in participant comments or inconsistency between responses to Likert and ranking questions. Several partial responses to ranking may have also hindered the weighted score calculations used to compare the strength of each potential barrier. Staff perceptions of top patient challenges appeared to vary by area of employment, but the study's limited sample size did not provide sufficient power for inferential statistical analysis. We also acknowledge that although staff knowledge of contraception is important, not all clinic staff require the same level of knowledge. Finally, we note the use of a nonvalidated survey instrument, since none currently exist.

Our survey of personnel at two practices identified numerous modifiable challenges to the provision of contraception, and found that provider and staff respondents exhibited inaccurate knowledge about contraception. Future research directions include discussion of potential quality improvement projects to address modifiable challenges, and staff education outreach. A similar survey could be useful for other health centers seeking to enhance contraception access.

\section{Tables and Figures}


Table 1: Barriers to Contraception Access Survey: Participant Demographics

\begin{tabular}{|c|c|c|c|c|}
\hline \multirow{2}{*}{$\begin{array}{c}\text { Characteristic Variable } \\
\text { Health Center Site }\end{array}$} & \multicolumn{2}{|c|}{ Provider $n(\%), \mathrm{N}=95$} & \multicolumn{2}{|c|}{ Staff $n(\%), N=76$} \\
\hline & HFM & St Margaret & HFM & St Margaret \\
\hline Total Number of Study Participants & $\mathrm{N}=\mathbf{4 0}$ & $\mathbf{N}=55$ & $N=53$ & $\mathbf{N}=\mathbf{2 3}$ \\
\hline $\begin{array}{l}\text { Age } \\
\text { n (\%) }\end{array}$ & $\mathrm{N}=39$ & $\mathrm{~N}=51$ & $\mathrm{~N}=51$ & $\mathrm{~N}=\mathbf{2 3}$ \\
\hline Less than 20 years & $0(0 \%)$ & $0(0 \%)$ & $1(2.0 \%)$ & $0(0 \%)$ \\
\hline $20-40$ years & $23(59.0 \%)$ & $38(74.5 \%)$ & $26(51.0 \%)$ & $9(39.1 \%)$ \\
\hline $41-60$ years & $10(25.6 \%)$ & $8(15.7 \%)$ & $20(39.2 \%)$ & $10(43.5 \%)$ \\
\hline Over 60 years & $6(15.4 \%)$ & $5(9.8 \%)$ & $4(7.8 \%)$ & $4(17.4 \%)$ \\
\hline $\begin{array}{l}\text { Gender } \\
\text { n (\%) }\end{array}$ & $\mathrm{N}=38$ & $N=51$ & $\mathrm{~N}=50$ & $\mathrm{~N}=\mathbf{2 3}$ \\
\hline Male & $11(28.9 \%)$ & $27(52.9 \%)$ & $1(2.0 \%)$ & $3(13.0 \%)$ \\
\hline Female & $27(71.1 \%)$ & $24(47.1 \%)$ & $48(96.0 \%)$ & $20(87.0 \%)$ \\
\hline Transgender male/female & $0(0 \%)$ & $0(0 \%)$ & $0(0 \%)$ & $0(0 \%)$ \\
\hline Other/preferred not to answer & $0(0 \%)$ & $0(0 \%)$ & $1(2.0 \%)$ & $0(0 \%)$ \\
\hline $\begin{array}{c}\text { Race/Ethnicity } \\
\text { n (\%) }\end{array}$ & $\mathrm{N}=38$ & $N=51$ & $\mathrm{~N}=50$ & $\mathrm{~N}=22$ \\
\hline Black & $0(0 \%)$ & $1(2.0 \%)$ & $12(24.0 \%)$ & $2(9.1 \%)$ \\
\hline Hispanic/Latino & $0(0 \%)$ & $1(2.0 \%)$ & $3(6.0 \%)$ & $0(0 \%)$ \\
\hline White & $32(84.2 \%)$ & $42(82.4 \%)$ & $29(58.0 \%)$ & $19(86.4 \%)$ \\
\hline Asian & $4(10.5 \%)$ & $6(11.8 \%)$ & $2(4.0 \%)$ & $0(0 \%)$ \\
\hline American Indian/Alaska Native/Pacific Islander & $0(0 \%)$ & $0(0 \%)$ & $0(0 \%)$ & $0(0 \%)$ \\
\hline Mixed & $1(2.6 \%)$ & $1(2.0 \%)$ & $3(6.0 \%)$ & $0(0 \%)$ \\
\hline Other & $1(2.6 \%)$ & $0(0 \%)$ & $1(2.0 \%)$ & $1(4.6 \%)$ \\
\hline $\begin{array}{c}\text { Area of Employment or Level of Medical } \\
\text { Training? } \\
n(\%)\end{array}$ & $\mathrm{N}=39$ & $\mathrm{~N}=51$ & $\mathrm{~N}=51$ & $\mathrm{~N}=\mathbf{2 3}$ \\
\hline Administrative & $\mathrm{N} / \mathrm{A}$ & $\mathrm{N} / \mathrm{A}$ & $1(2.0 \%)$ & $2(8.7 \%)$ \\
\hline Secretary & $\mathrm{N} / \mathrm{A}$ & N/A & $15(29.4 \%)$ & $1(4.4 \%)$ \\
\hline Medical assistant & N/A & N/A & $15(29.4 \%)$ & $7(30.4 \%)$ \\
\hline Nurse & N/A & $N / A$ & $12(23.5 \%)$ & $10(43.5 \%)$ \\
\hline Social work & $\mathrm{N} / \mathrm{A}$ & $\mathrm{N} / \mathrm{A}$ & $3(5.9 \%)$ & $3(13.0 \%)$ \\
\hline Care manager & $\mathrm{N} / \mathrm{A}$ & $\mathrm{N} / \mathrm{A}$ & $5(9.8 \%)$ & $0(0 \%)$ \\
\hline First-year resident & $2(5.1 \%)$ & $11(21.6 \%)$ & $\mathrm{N} / \mathrm{A}$ & $\mathrm{N} / \mathrm{A}$ \\
\hline Second-year resident & $2(5.1 \%)$ & $6(11.8 \%)$ & $\mathrm{N} / \mathrm{A}$ & $\mathrm{N} / \mathrm{A}$ \\
\hline Third-year resident & $8(20.5 \%)$ & $9(17.7 \%)$ & $\mathrm{N} / \mathrm{A}$ & $\mathrm{N} / \mathrm{A}$ \\
\hline Chief resident & $1(2.6 \%)$ & $0(0 \%)$ & $\mathrm{N} / \mathrm{A}$ & $\mathrm{N} / \mathrm{A}$ \\
\hline Fellow & $1(2.6 \%)$ & $3(5.9 \%)$ & $\mathrm{N} / \mathrm{A}$ & $\mathrm{N} / \mathrm{A}$ \\
\hline Faculty MD/DO & $17(43.6 \%)$ & $22(43.1 \%)$ & $\mathrm{N} / \mathrm{A}$ & $\mathrm{N} / \mathrm{A}$ \\
\hline Nurse practitioner/physician assistant & $8(20.5 \%)$ & $0(0 \%)$ & $\mathrm{N} / \mathrm{A}$ & $\mathrm{N} / \mathrm{A}$ \\
\hline $\begin{array}{l}\text { What aspects of maternity care do you work in? } \\
\mathrm{n}(\%)\end{array}$ & $\mathrm{N}=39$ & $N=51$ & N/A & N/A \\
\hline Outpatient prenatal only & $10(25.6 \%)$ & $15(29.4 \%)$ & $\mathrm{N} / \mathrm{A}$ & $\mathrm{N} / \mathrm{A}$ \\
\hline Outpatient prenatal and deliveries & $18(46.2 \%)$ & $28(54.9 \%)$ & $\mathrm{N} / \mathrm{A}$ & $\mathrm{N} / \mathrm{A}$ \\
\hline None & $11(28.2 \%)$ & $8(15.7 \%)$ & $\mathrm{N} / \mathrm{A}$ & $\mathrm{N} / \mathrm{A}$ \\
\hline
\end{tabular}


Figure 1: Barriers to Contraception Access Survey: Combined Provider and Staff

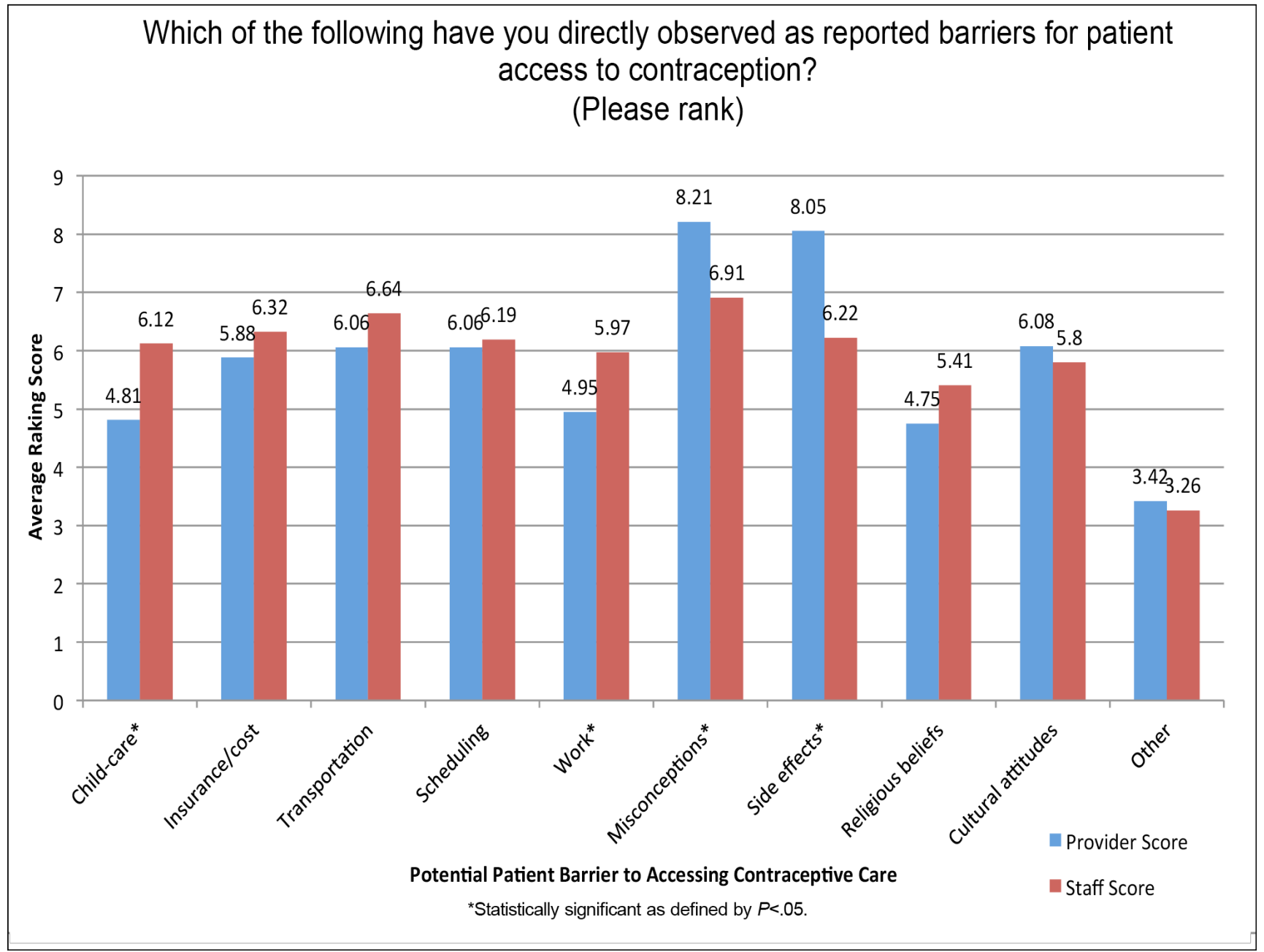


Figure 2: Barriers to Contraception Access Survey: Provider Identified

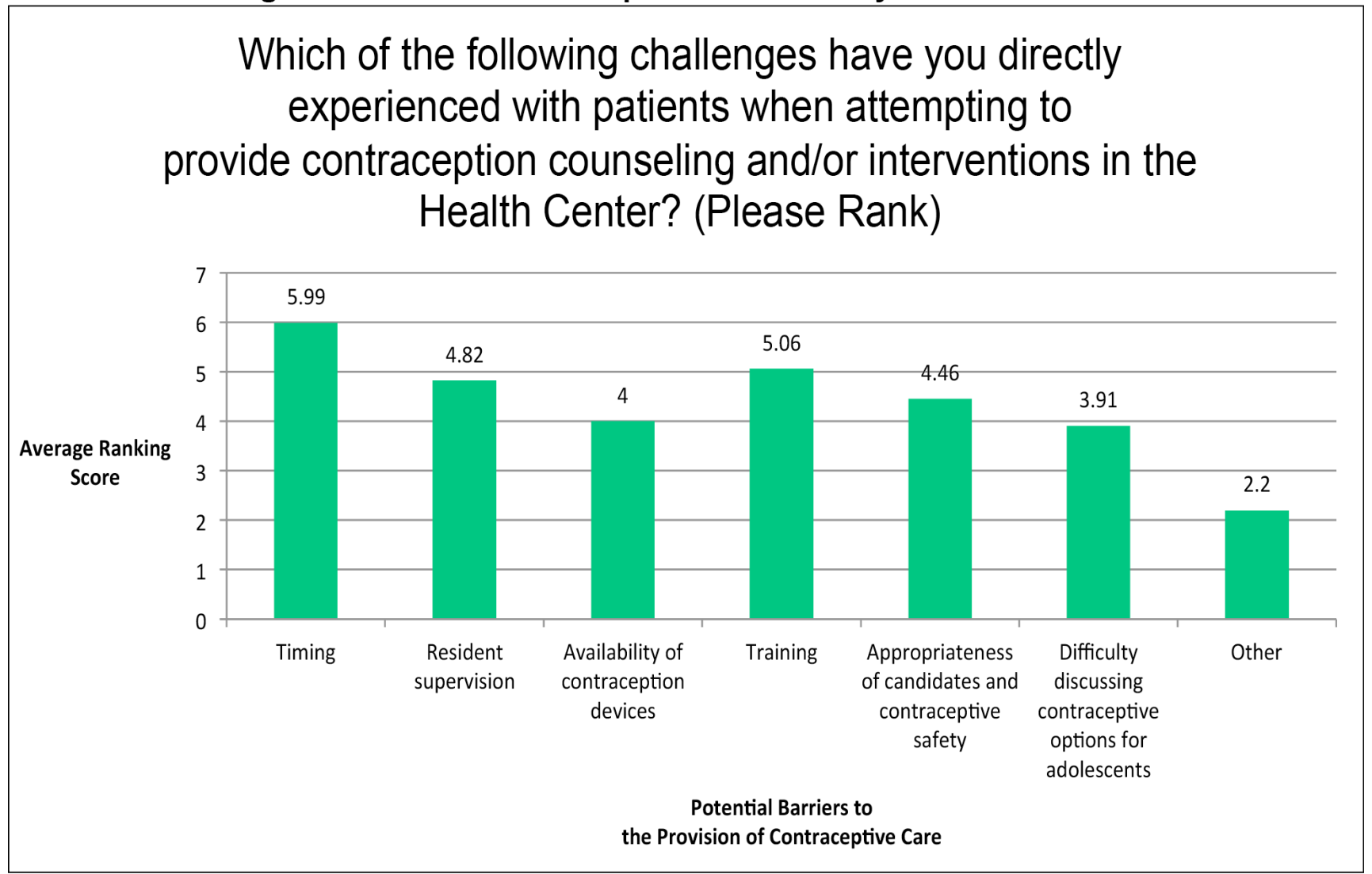

Figure 3: Barriers to Contraception Access Survey: Staff Identified

$$
\begin{aligned}
& \text { Which of the following have you directly } \\
& \text { experienced with patients in providing contraception } \\
& \text { interventions in the Health Center? (Please Rank) }
\end{aligned}
$$

Average Ranking Score

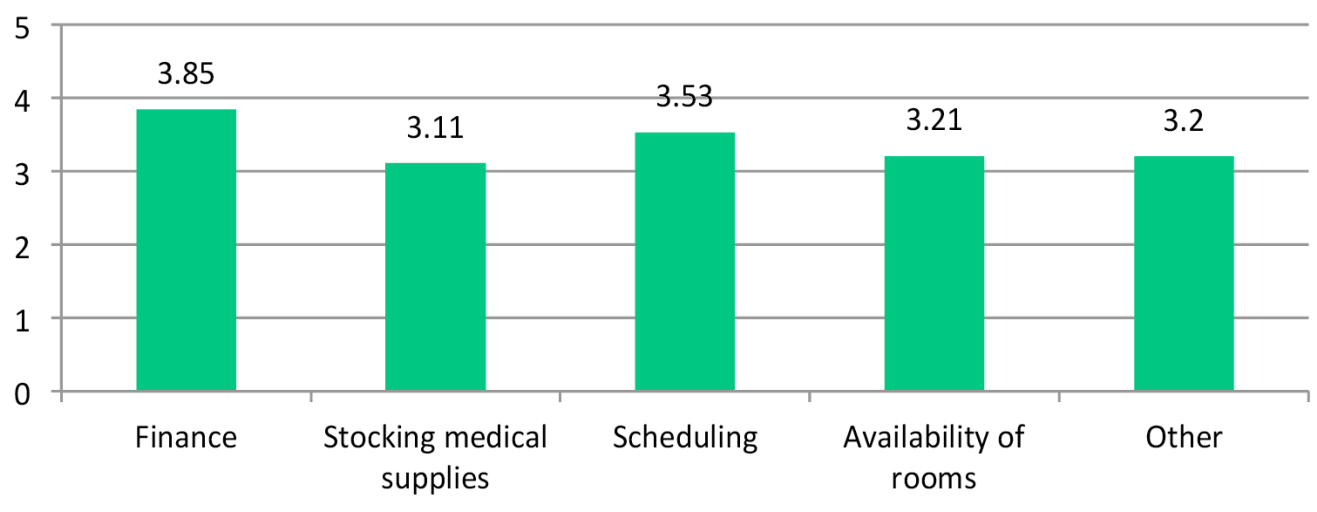

Potential Barriers to the Provision of Contraceptive Care 
Table 2: Barriers to Contraception Access Survey: Contraception Knowledge

\begin{tabular}{|c|c|c|c|c|c|}
\hline \multicolumn{2}{|r|}{ Knowledge Question } & \multicolumn{4}{|c|}{ Answers by Health Center and Employment Type } \\
\hline & & HFM Provider & HFM Staff & $\begin{array}{l}\text { St Margaret } \\
\text { Provider }\end{array}$ & $\begin{array}{l}\text { St Margaret } \\
\text { Staff }\end{array}$ \\
\hline 1 & $\begin{array}{l}\text { LARC is appropriate for adolescents and nulliparous } \\
\text { women. (T/F) }\end{array}$ & $100 \%$ correct & $94.1 \%$ correct & $96 \%$ correct & $87 \%$ correct \\
\hline 2 & $\begin{array}{l}\text { ACOG guidelines recommend the use of routine } \\
\text { prophylactic antibiotics at the time of IUD insertion } \\
\text { to decrease risk of pelvic infection. }(T / F)^{*}\end{array}$ & $97.1 \%$ correct & $58.8 \%$ correct & $98 \%$ correct & $82.6 \%$ correct \\
\hline 3 & $\begin{array}{l}\text { History of previous ectopic pregnancy is a } \\
\text { contraindication for IUD } \\
\text { contraception. (T/F) }\end{array}$ & $94.1 \%$ correct & $59.4 \%$ correct & $76 \%$ correct & $65.2 \%$ correct \\
\hline 4 & $\begin{array}{l}\text { Immediate postpartum insertion of LARC is safe. } \\
(\mathrm{T} / \mathrm{F})^{\star}\end{array}$ & $97.1 \%$ correct & $50 \%$ correct & $78 \%$ correct & $39.1 \%$ correct \\
\hline 5 & $\begin{array}{l}\text { Which of the following are required prior to inserting } \\
\text { an IUD in an asymptomatic patient according } \\
\text { to ACOG guidelines? (Pap smear, }{ }^{*} \text { STI testing, } \\
\text { pregnancy test, }{ }^{\dagger} \\
\text { none }^{\star+} \text { ) }\end{array}$ & $\begin{array}{l}\text { Pap smear } \\
(2.90 \%) ; \\
\text { STI testing } \\
(35.3 \%) ; \\
\text { pregnancy test } \\
(85.3 \%) ; \text { none } \\
(11.8 \%)\end{array}$ & $\begin{array}{l}\text { Pap smear } \\
(27.3 \%) ; \\
\text { STI testing } \\
(30.3 \%) ; \\
\text { pregnancy test } \\
(93.9 \%) ; \text { none } \\
(0 \%)\end{array}$ & $\begin{array}{l}\text { Pap smear } \\
(14.0 \%) ; \\
\text { STI testing } \\
(36 \%) ; \\
\text { pregnancy test } \\
(94 \%) ; \\
\text { none }(4 \%)\end{array}$ & $\begin{array}{l}\text { Pap smear } \\
(34.8 \%) ; \\
\text { STI testing } \\
(69.6 \%) ; \\
\text { pregnancy } \\
\text { test }(95.7 \%) \text {; } \\
\text { none }(0 \%)\end{array}$ \\
\hline
\end{tabular}

*Statistically significant at $P<0.05$ in the comparison of provider and staff responses.

†IUD can be inserted if there is a negative pregnancy test or if the provider determines it is reasonably certain that a woman is not pregnant without needing a pregnancy test.

\section{Acknowledgments}

Content from this article was presented at the Society of Teachers of Family Medicine Annual Spring Conference, May 5-9 2018 in Washington, DC.

\section{Corresponding Author}

Lauren Cowen

University of Rochester School of Medicine and Dentistry, 601 Elmwood Ave, Box 233, Rochester, NY 14642.

585-330-0525. Fax: 585-442-8319

lauren_cowen@urmc.rochester.edu

\section{Author Affiliations}

Lauren Cowen - University of Rochester Family Medicine Residency, Rochester, NY

Scott G. Hartman, MD - University of Rochester Medical Center, Rochester, NY

Elizabeth Loomis, MD - University of Rochester Family Medicine Residency, Rochester, NY

Sukanya Srinivasan, MD, MPH - University of Pittsburgh Medical Center St Margaret Family Medicine Residency,

Pittsburgh, PA

Christina Gasbarro, MD - University of Pittsburgh Medical Center St Margaret Family Medicine Residency, Pittsburgh, PA

Jocelyn Young, DO - University of Rochester Family Medicine Residency, Rochester, NY

\section{References}

1. Conde-Agudelo A, Rosas-Bermúdez A, Kafury-Goeta AC. Birth spacing and risk of adverse perinatal outcomes: a meta-analysis. JAMA. 2006;295(15):1809-1823. https://doi.org/10.1001/jama.295.15.1809

2. Behrman RE, Butler AS, eds. Preterm Birth: Causes, Consequences, and Prevention: Institute of Medicine Brief Report. Washington, DC: National Academies Press; July 2006.

3. Kahn RS, Wise PH, Finkelstein JA, Bernstein HH, Lowe JA, Homer CJ. The scope of unmet maternal health needs in pediatric settings. Pediatrics. 1999;103(3):576-581. https://doi.org/10.1542/peds.103.3.576 
4. Family Medicine Education Consortium. Full description of the network. http://www.fmec.net /implicitnetwork.htm

5. Taggart C, Matthews A, Holub D, et al. Culturally-Sensitive Interconception Care: A Model of Implementation and Selected Project Data. Presentation at Society of Teachers of Family Medicine Annual Spring Conference, May 2016, Minneapolis, MN.

6. Hopkins B. Barriers to health care providers' provision of long-acting reversible contraception to adolescent and nulliparous young women. Nurs Womens Health. 2017;21(2):122-128. https://doi.org/10.1016 /j.nwh.2017.02.007

7. Thaxton L, Espey E. Family planning American style redux: unintended pregnancy improves, barriers remain. Obstet Gynecol Clin North Am. 2017;44(1):41-56. https://doi.org/10.1016/j.ogc.2016.11.001

8. Carvajal DN, Gioia D, Mudafort ER, Brown PB, Barnet B. How can primary care physicians best support contraceptive decision making? A qualitative study exploring the perspectives of Baltimore Latinas. Womens Health Issues. 2017;27(2):158-166. https://doi.org/10.1016/j.whi.2016.09.015

9. Clare C, Squire MB, Alvarez K, Meisler J, Fraser C. Barriers to adolescent contraception use and adherence. Int J Adolesc Med Health. 2016;30(4). https://doi.org/10.1515/ijamh-2016-0098

10. Harney C, Dude A, Haider S. Factors associated with short interpregnancy interval in women who plan postpartum LARC: a retrospective study. Contraception. 2017;95(3):245-250. https://doi.org/10.1016 /j.contraception.2016.08.012

11. Kumar N, Brown JD. Access barriers to long-acting reversible contraceptives for adolescents. J Adolesc Health. 2016;59(3):248-253. https://doi.org/10.1016/j.jadohealth.2016.03.039

12. Politi MC, Estlund A, Milne A, Buckel CM, Peipert JF, Madden T. Barriers and facilitators to implementing a patient-centered model of contraceptive provision in community health centers. Contracept Reprod Med. 2016;1(21):21. https://doi.org/10.1186/s40834-016-0032-3

13. Murphy MK, Stoffel C, Nolan M, Haider S. Interdependent barriers to providing adolescents with long-acting reversible contraception: qualitative insights from providers. J Pediatr Adolesc Gynecol. 2016;29(5):436-442. https://doi.org/10.1016/j.jpag.2016.01.125

14. Kavanaugh ML, Jerman J, Ethier K, Moskosky S. Meeting the contraceptive needs of teens and young adults: youth-friendly and long-acting reversible contraceptive services in US family planning facilities. J Adolesc Health. 2013;52(3):284-292. https://doi.org/10.1016/j.jadohealth.2012.10.276

15. Cowen L, Hartman S, Loomis E, Srinivasan S, Gasbarro C, Young J. Barriers to Contraception Access Survey. STFM Resource Library. https://resourcelibrary.stfm.org/viewdocument/barriers-to-contraception-accesssu?CommunityKey=2751b51d-483f-45e2-81 de-4faced0a290a\&tab=librarydocuments. 2017. Accessed January 24, 2019.

Copyright $\odot 2019$ by the Society of Teachers of Family Medicine 